Supplement of Hydrol. Earth Syst. Sci., 21, 6425-6444, 2017

https://doi.org/10.5194/hess-21-6425-2017-supplement

(c) Author(s) 2017. This work is distributed under

the Creative Commons Attribution 3.0 License.

(c) (1)

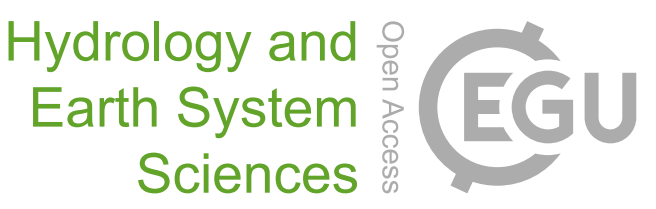

Supplement of

\title{
Prediction of storm transfers and annual loads with data-based mechanistic models using high-frequency data
}

Mary C. Ockenden et al.

Correspondence to: Philip M. Haygarth (p.haygarth@lancaster.ac.uk)

The copyright of individual parts of the supplement might differ from the CC BY 3.0 License. 
Supplementary Information

\section{Contents}

Pages: 28

Sections: 2

Tables: 5

Figures: 18

References: 6 


\section{Section S1}

Estimation of hourly rainfall time series for the Wylye catchment

Rainfall data were obtained from the Demonstration Test Catchment (DTC) Programme and the Environment Agency (EA) as follows:

\begin{tabular}{|l|l|l|l|l|}
\hline Source & Site & $\begin{array}{l}\text { Easting } \\
(\mathrm{m})\end{array}$ & $\begin{array}{l}\text { Northing } \\
(\mathrm{m})\end{array}$ & Data format \\
\hline DTC & Brixton Deverill & 385600 & 137900 & Daily, 9am to 9am \\
\hline DTC & Norton Ferris & 379000 & 136466 & Daily, 9am to 9am \\
\hline EA & Frome & 377364 & 148748 & Raw tipping bucket times with QA flags \\
\hline EA & Gillingham & 380310 & 125840 & Raw tipping bucket times with QA flags \\
\hline EA & Penridge & 375350 & 131860 & Raw tipping bucket times with QA flags \\
\hline EA & Tisbury & 395694 & 129843 & Raw tipping bucket times with QA flags \\
\hline EA & Walters Farm & 372649 & 137298 & Raw tipping bucket times with QA flags \\
\hline
\end{tabular}

The EA gauges were all outside the Wylye catchment; locations are shown in Figure 1c (main manuscript). Only data flagged $\mathrm{G}$ (good) was used from tipping bucket data, analysed to give hourly time series. For periods where tips were not marked ' $G$ ', hourly time series were filled with $\mathrm{NaN}$ (not a number), to signify missing data rather than no rain. For the hourly time series, cross correlation between sites indicated that the sites with highest cross correlation were Gillingham, Penridge and Walters Farm (cross correlation 0.73 - 0.80, at zero time lag). Hourly datasets were aggregated to daily (9am to 9am) and regressed with the daily datasets from Brixton Deverill (catchment outlet) and Norton Ferris (in W of catchment) to assess total rainfall volume and how representative each one was of rainfall in the catchment. The datasets most closely aligned with Brixton Deverill and Norton Ferris were Gillingham, Penridge and Walters Farm $\left(\mathrm{R}^{2}\right.$ between 0.79 and 0.90$)$. As all the datasets had some missing data, a combined dataset taking the mean (discounting missing data) of sites Gillingham, Penridge and Walters Farm was used to create an hourly dataset from 1 January 2011 - 31 May 2014. This dataset was used for transfer function modelling. 


\section{Section S2}

Model assessment criteria

Model fit was assessed according to $\mathrm{R}_{\mathrm{t}}^{2}$ (akin to Nash Sutcliffe Efficiency):

$R_{t}^{2}=1-\frac{\hat{\sigma}^{2}}{\sigma_{y}^{2}} ;$

where $\hat{\sigma}^{2}=\frac{1}{N} \sum_{i=1}^{N}\left[\hat{y}_{i}-y_{i}\right]^{2} ; \quad \sigma_{y}^{2}=\frac{1}{N} \sum_{i=1}^{N}\left[y_{i}-\bar{y}\right]^{2} ; \bar{y}=\frac{1}{N} \sum_{i=1}^{N} y_{i}$

$\hat{y}_{i}$ are the model estimations, $y_{i}$ are the observations, $\hat{\sigma}^{2}$ is the variance estimate of the model residuals (only equal if the mean of residuals is identically zero) and $\sigma_{y}^{2}$ is the variance of the observations.

Systematic over- or under-prediction of the model was evaluated with model bias:

Model bias $=100 * \sum\left[\widehat{y}_{i}-y_{i}\right] / \sum y_{i}$

A balance of model fit and over-parameterisation was sought using the Young Information Criterion (YIC) (Young, 1984) and visual inspection of the model fit to the monitoring data.

$Y I C=\log _{e} \frac{\hat{\sigma}^{2}}{\sigma_{y}^{2}}+\log _{e}\{N E V N\}$

where NEVN is the normalised error variance norm defined as:

$$
N E V N=\frac{1}{n p} \sum_{i=1}^{n p} \frac{\hat{\sigma}^{2} \hat{P}_{i i}}{\hat{a}_{i}^{2}}
$$

np is the number of parameters estimated, $\hat{P}_{i i}$ is the ith diagonal on the parameter covariance matrix, $\hat{a}_{i}^{2}$ is the square of the ith parameter. The first term in YIC is based on the coefficient of determination and is a measure of how well the model explains the data (the smaller the model residuals, the more negative this term becomes). The second term is a measure of the over-parameterisation; generally, a higher order model will capture more of the dynamics of the system, but with higher uncertainty in the parameter estimates. In that case the second term in YIC will dominate. Thus YIC is a compromise between the fit of the model and model complexity. 
Table S1 Study catchment characteristics

\begin{tabular}{|c|c|c|c|}
\hline Catchment & $\begin{array}{l}\text { Newby Beck at } \\
\text { Newby }\end{array}$ & $\begin{array}{l}\text { Blackwater at Park } \\
\text { Farm }\end{array}$ & $\begin{array}{l}\text { Wylye at Brixton } \\
\text { Deverill }\end{array}$ \\
\hline Part of DTC catchment & Eden, Cumbria & Wensum, Norfolk & Avon, Hampshire \\
\hline $\begin{array}{l}\text { Sampling location at } \\
\text { catchment outlet }\end{array}$ & $54.59^{\circ} \mathrm{N}, 2.62^{\circ} \mathrm{W}$ & $52.78^{\circ} \mathrm{N}, 1.15^{\circ} \mathrm{E}$ & $51.16^{\circ} \mathrm{N}, 2.19^{\circ} \mathrm{W}$ \\
\hline $\begin{array}{l}\text { Elevation of sampling } \\
\text { location (m a.s.l.) }\end{array}$ & 233 & 43 & 189 \\
\hline Size of catchment $\left(\mathrm{km}^{2}\right)$ & 12.5 & 19.7 & 50.2 \\
\hline Aspect $\left({ }^{\circ}\right.$ from North) & $28^{\circ}$ & $144^{\circ}$ & $106^{\circ}$ \\
\hline $\begin{array}{l}\text { Mean (and standard } \\
\text { deviation) annual } \\
\text { rainfall }^{\mathrm{a}}(\mathrm{mm})\end{array}$ & $1262(220)$ & $995(142)$ & $714(109)$ \\
\hline Baseflow index ${ }^{\mathrm{b}}$ & 0.39 & 0.80 & 0.93 \\
\hline Soils $^{\mathrm{c}}$ & $\begin{array}{l}\text { Clay loam and sandy } \\
\text { clay loam soils; } \\
\text { Brickfield 3, } \\
\text { Waltham and Clifton } \\
\text { soil associations }\end{array}$ & $\begin{array}{l}\text { Chalky boulder } \\
\text { clay and sandy } \\
\text { loam soils; Beccles } \\
1 \text {, Burlingham } 1 \\
\text { and Wick } 2 \text { and } 3 \\
\text { soil associations }\end{array}$ & $\begin{array}{l}\text { Sandy loam and } \\
\text { silty clay loam } \\
\text { soils; Ardington, } \\
\text { Blewbury, Coombe } \\
\text { 1, Upton 1, and } \\
\text { Icknield soil } \\
\text { associations }\end{array}$ \\
\hline Geology & $\begin{array}{l}\text { Glacial till over } \\
\text { Carboniferous } \\
\text { limestone }\end{array}$ & $\begin{array}{l}\text { Quaternary glacial } \\
\text { till, sands and } \\
\text { gravels over } \\
\text { Pleistocene Crag } \\
\text { and Cretaceous } \\
\text { Chalk }\end{array}$ & $\begin{array}{l}\text { Cretaceous Chalk } \\
\text { and Upper } \\
\text { Greensand }\end{array}$ \\
\hline Land use & Livestock & Arable crops & $\begin{array}{l}\text { Livestock and } \\
\text { cereals }\end{array}$ \\
\hline
\end{tabular}

${ }^{a}$ From UKCP Gridded Observation Data, 1981 - 2011 (Met Office, 2009)

${ }^{\mathrm{b}}$ From Flood Estimation Handbook (Robson and Reed, 1999)

${ }^{c}$ From Soil Survey of England and Wales (Soil Survey of England and Wales, 1983) 
Table S2 Notation

\begin{tabular}{|c|c|}
\hline$a_{\mathrm{f}}, a_{\mathrm{s}}$ & $\begin{array}{l}\text { Parameters in the denominator polynomials of the partial fraction expansion into } \\
\text { parallel, first order transfer functions (see SI Table S3) }\end{array}$ \\
\hline$b_{\mathrm{f}}, b_{\mathrm{s}}$ & $\begin{array}{l}\text { Parameters in the numerator polynomials of the partial fraction expansion into } \\
\text { parallel, first order transfer functions (see SI Table S3) }\end{array}$ \\
\hline$\beta$ & A constant exponent in the rainfall non-linearity (see Eq. 4) \\
\hline$\delta$ & Pure time delay in a discrete-time model (see SI Table S3, Eq. S6 and S7) \\
\hline $\mathrm{m}$ & Order of the numerator polynomial \\
\hline $\mathrm{n}$ & Order of the denominator polynomial \\
\hline NSE & Nash Sutcliffe Efficiency (see also $\mathrm{R}_{\mathrm{t}}^{2}$ ) \\
\hline$Q(t)$ & Discharge at time $t$ \\
\hline$R(t)$ & Rainfall at time $t$ \\
\hline $\operatorname{Re}(t)$ & Effective rainfall at time $t$ \\
\hline $\mathrm{R}_{\mathrm{t}}^{2}$ & Model fit = $1-$ variance estimate of model residuals/variance of observations \\
\hline$\sigma_{y}^{2}$ & Variance of observations $=\frac{1}{N} \sum_{i=1}^{N}\left[y_{i}-\bar{y}\right]^{2}$ \\
\hline$\hat{\sigma}^{2}$ & Variance estimate of model residuals $=\frac{1}{N} \sum_{i=1}^{N}\left[\hat{y}_{i}-y_{i}\right]^{2}$ \\
\hline TPload(t) & Total phosphorus load during time step ending at time $t$ \\
\hline$\tau$ & Time delay in a continuous-time model (see SI Table S3, Eq. S8 and S9) \\
\hline$y_{i}$ & Observation at ith time step \\
\hline $\bar{y}$ & Mean of observations $=\frac{1}{N} \sum_{i=1}^{N} y_{i}$ \\
\hline$\hat{y}_{i}$ & Model prediction at ith time step \\
\hline YIC & Young Information Criterion (see SI Section S2, Eq. S4) \\
\hline
\end{tabular}


Table S3 Structure of models and relationship between parameters from discrete-time and continuous-time models (from Ockenden et al., 2017)

\section{Structure: Discrete time}

A second-order discrete linear transfer function with no noise model, denoted by $[2,2, \delta]$ takes the form:

$$
y(t)=\frac{b_{1}+b_{2} z^{-1}}{1+a_{1} z^{-1}+a_{2} z^{-2}} u(t-\delta)
$$

where $y(t)$ is model output at time $t, u(t)$ is model input, $z^{-1}$ is the backwards step operator i.e. $z^{-1} y(t)=y(t-1) . b_{1}, b_{2}, a_{1}, a_{2}$ are parameters determined during model identification and $\delta$ is the number of time steps of pure time delay. For a physical interpretation, models are only accepted it they can be decomposed by partial fraction expansion into two first order transfer functions with structure $[1,1, \delta]$ representing fast and slow pathways, with characteristic time constants and steady state gains, i.e.

$$
y(t)=\frac{b_{\mathrm{f}}}{1-a_{\mathrm{f}} z^{-1}} u(t-\delta)+\frac{b_{\mathrm{s}}}{1-a_{\mathrm{s}} z^{-1}} u(t-\delta)
$$

where $b_{\mathrm{f}}$ and $b_{\mathrm{s}}$ are gains on the fast and slow pathways, respectively, and $a_{\mathrm{f}}$ and $a_{\mathrm{s}}$ are parameters characterising the time constants of the fast and slow pathways respectively. $a_{\mathrm{f}}$ and $a_{\mathrm{s}}$ are roots of the denominator polynomial in the second order transfer functions above (Eq. S6).

\section{Structure: Continuous-time}

A second order continuous-time linear transfer function with no noise model takes the form:

$$
Y(s)=\frac{b_{1} s+b_{2}}{s^{2}+a_{1} s+a_{2}} e^{-s \tau} U(s)
$$

where, $Y(s)$ and $U(s)$ represent the Laplace transforms of the output and input, respectively. $b_{1}, b_{2}, a_{1}, a_{2}$ are parameters in the denominator and numerator polynomials in the derivative operator $s=\frac{\mathrm{d}}{\mathrm{d} t}$ that define the relationship between the input and the output, and $\tau$ represents the delay. Models are only accepted if they can be decomposed by partial fraction expansion into two parallel, first-order transfer functions i.e.

$$
Y=\frac{b_{\mathrm{f}}}{s+a_{\mathrm{f}}} e^{-s \tau} U+\frac{b_{\mathrm{s}}}{s+a_{\mathrm{s}}} e^{-s \tau} U
$$

where $a_{\mathrm{f}}$ and $a_{\mathrm{s}}$ are direct reciprocals of the fast and slow time constants respectively, which define the fast and slow components of the response. $b_{\mathrm{f}}$ and $b_{\mathrm{s}}$ are parameters which determine the gain of the fast and slow components, respectively. 


\section{Relationship between parameters for discrete-time and continuous-time models}

Parameters $b_{1}, b_{2}, a_{1}, a_{2}$ (and parameters $b_{\mathrm{f}}, b_{\mathrm{s}}, a_{\mathrm{f}}, a_{\mathrm{s}}$ ) have different interpretation, and therefore different values between discrete-time and continuous-time models. The relationship between the parameters (see most Control Engineering textbooks, (e.g. Franklin et al., 2002) between discrete model denoted by superscript $\mathrm{d}$ and continuous time model denoted by superscript $\mathrm{c}$ is as follows:

for instance, for denominator parameter $a_{\mathrm{f}}$

$$
a_{\mathrm{f}}^{\mathrm{d}}=e^{-a_{\mathrm{f}}^{\mathrm{c}} \Delta t}
$$

while for $b_{\mathrm{f}}$ we have:

$$
b_{\mathrm{f}}^{\mathrm{d}}=\frac{b_{\mathrm{f}}^{\mathrm{c}}}{a_{\mathrm{f}}^{\mathrm{c}}}\left(1-e^{-a_{\mathrm{f}}^{\mathrm{c}} \Delta t}\right)
$$


Table S4 Definition of time constants, steady state gains and fraction on each pathway for discrete-time and continuous-time models, e.g. for second order model, following partial fraction decomposition according to SI Eq. S7 (discrete-time) or SI Eq. S9 (continuous-time)

\begin{tabular}{|l|l|l|}
\hline & Discrete-time & Continuous-time \\
\hline Time constants (fast, slow) & $\frac{\Delta T}{-\log _{\mathrm{e}}\left(a_{\mathrm{f}}^{\mathrm{d}}\right)} ; \frac{\Delta T}{-\log _{\mathrm{e}}\left(a_{\mathrm{s}}^{\mathrm{d}}\right)}$ & $\frac{1}{a_{\mathrm{f}}^{\mathrm{c}}} ; \frac{1}{a_{\mathrm{f}}^{\mathrm{c}}}$ \\
\hline Steady state gains & $S S G_{1}=\frac{b_{\mathrm{f}}^{\mathrm{d}}}{1-a_{\mathrm{f}}^{\mathrm{d}}} ; S S G_{2}=\frac{b_{\mathrm{s}}^{\mathrm{d}}}{1-a_{\mathrm{s}}^{\mathrm{d}}}$ & $S S G_{1}=\frac{b_{\mathrm{f}}^{\mathrm{c}}}{a_{\mathrm{f}}^{\mathrm{c}}} ; S S G_{2}=\frac{b_{\mathrm{f}}^{\mathrm{c}}}{a_{\mathrm{f}}^{\mathrm{c}}}$ \\
\hline Fraction on each pathway & $\frac{S S G_{1}}{S S G_{1}+S S G_{2}} ; \frac{S S G_{2}}{S S G_{1}+S S G_{2}}$ & $\frac{S S G_{1}}{S S G_{1}+S S G_{2}} ; \frac{S S G_{2}}{S S G_{1}+S S G_{2}}$ \\
\hline
\end{tabular}


Table S5

Model structure and parameters identified, including uncertainty from 10,000 Monte Carlo realisations (from Ockenden et al., 2017)

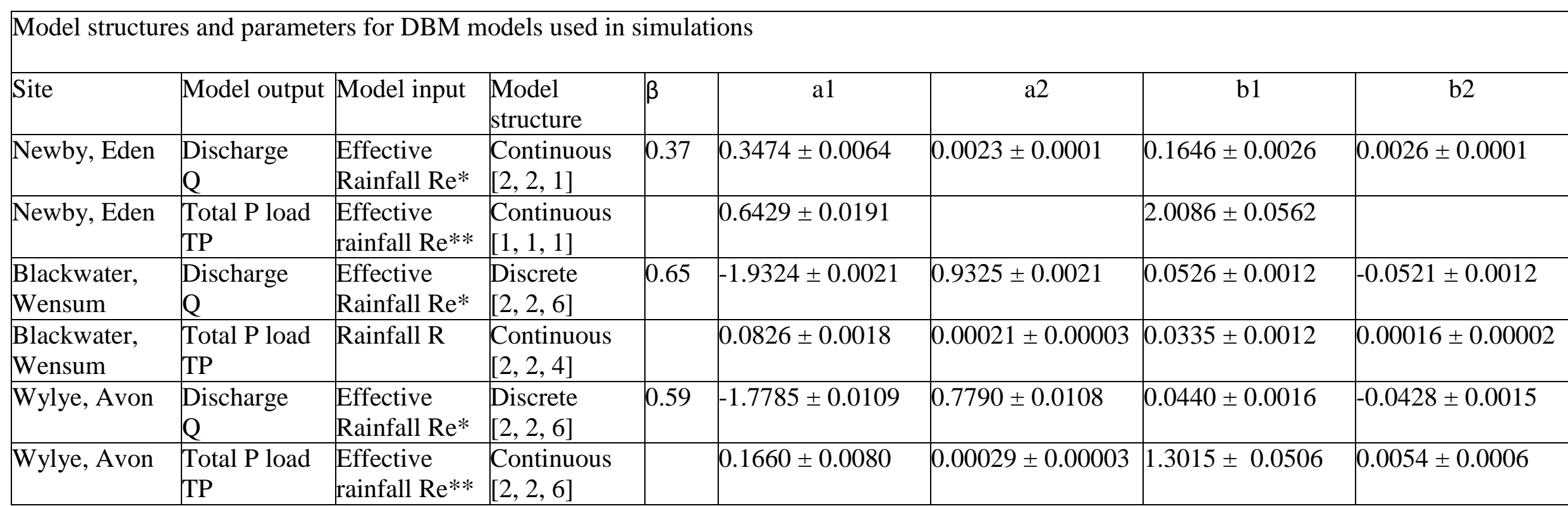

*where effective rainfall is used as input to the linear DBM discharge model, this is estimated at the same time as the model parameters, using rainfall $\mathrm{R}$ as input

**where effective rainfall is used as input to the linear DBM TPload model, this is first calculated using the previously estimated parameters for the discharge model 


\section{Figure S1}

Hourly streamflow (Q) against total phosphorus (TP) concentration for the Newby Beck catchment, with the rising limb of storm hydrographs in blue and the falling limb of hydrographs in red.

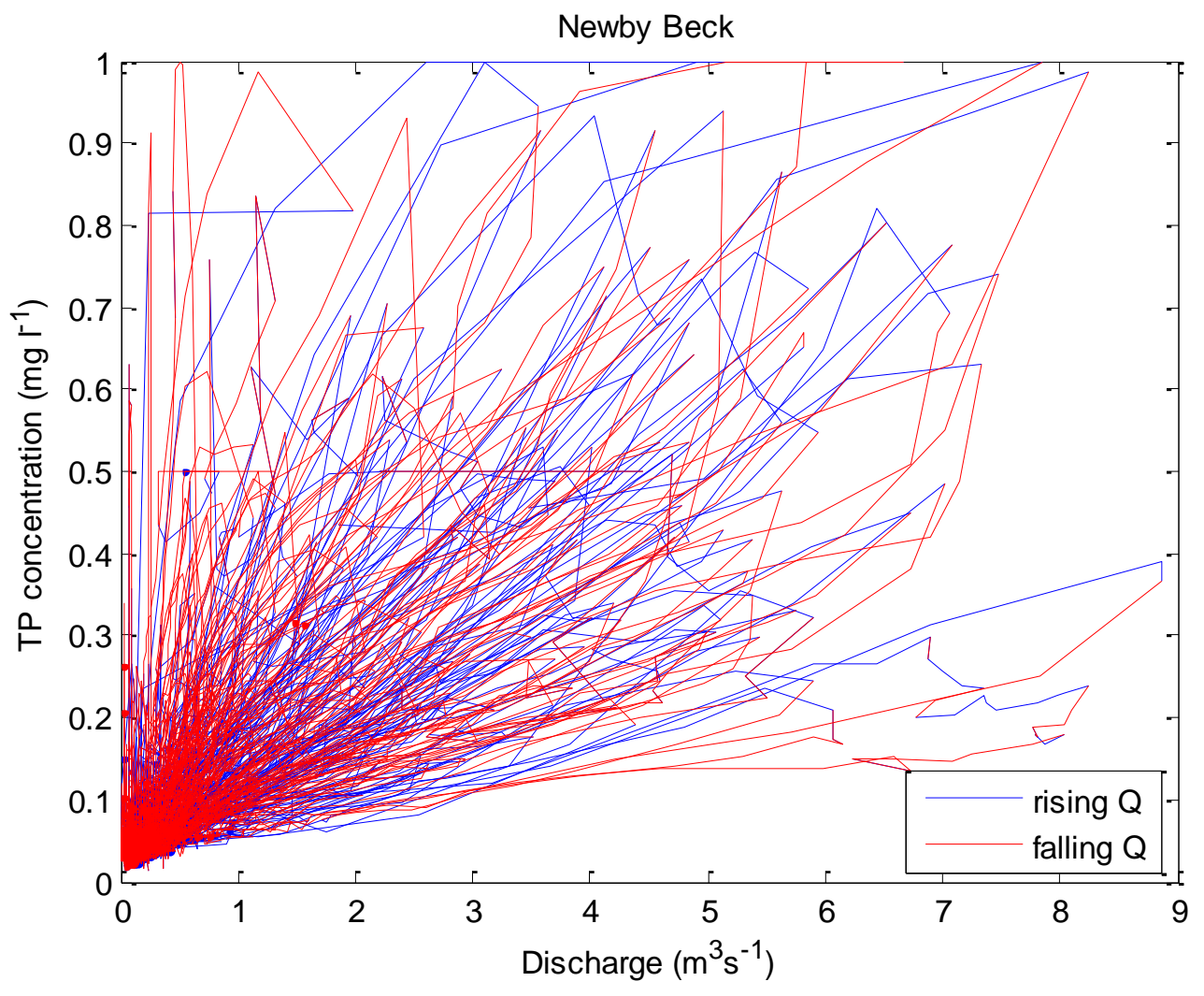


Figure S2

Hourly streamflow (Q) against total phosphorus (TP) concentration for the Blackwater catchment, with the rising limb of storm hydrographs in blue and the falling limb of hydrographs in red.

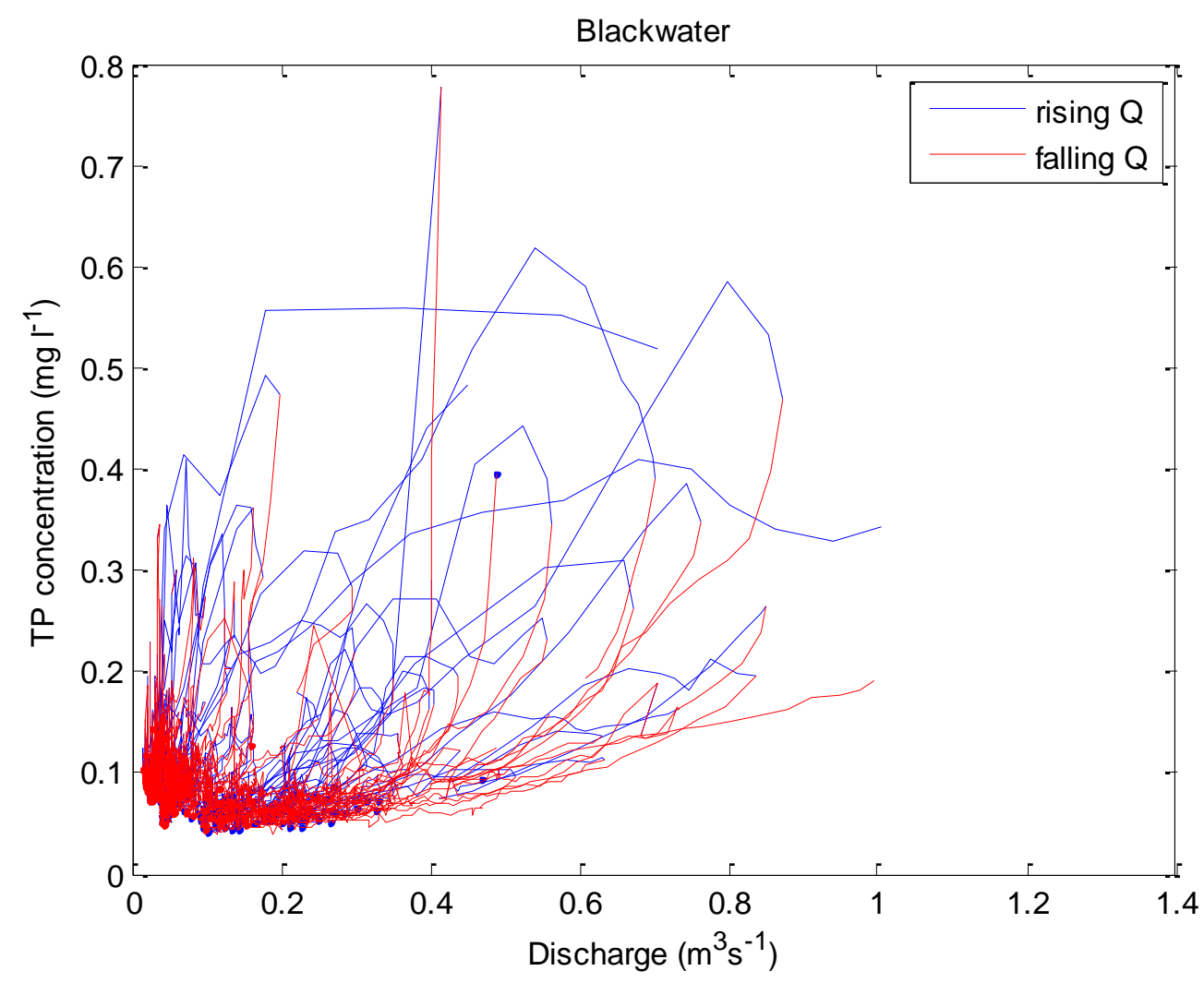


Figure S3

Hourly streamflow (Q) against total phosphorus (TP) concentration for the Wylye catchment, with the rising limb of storm hydrographs in blue and the falling limb of hydrographs in red.

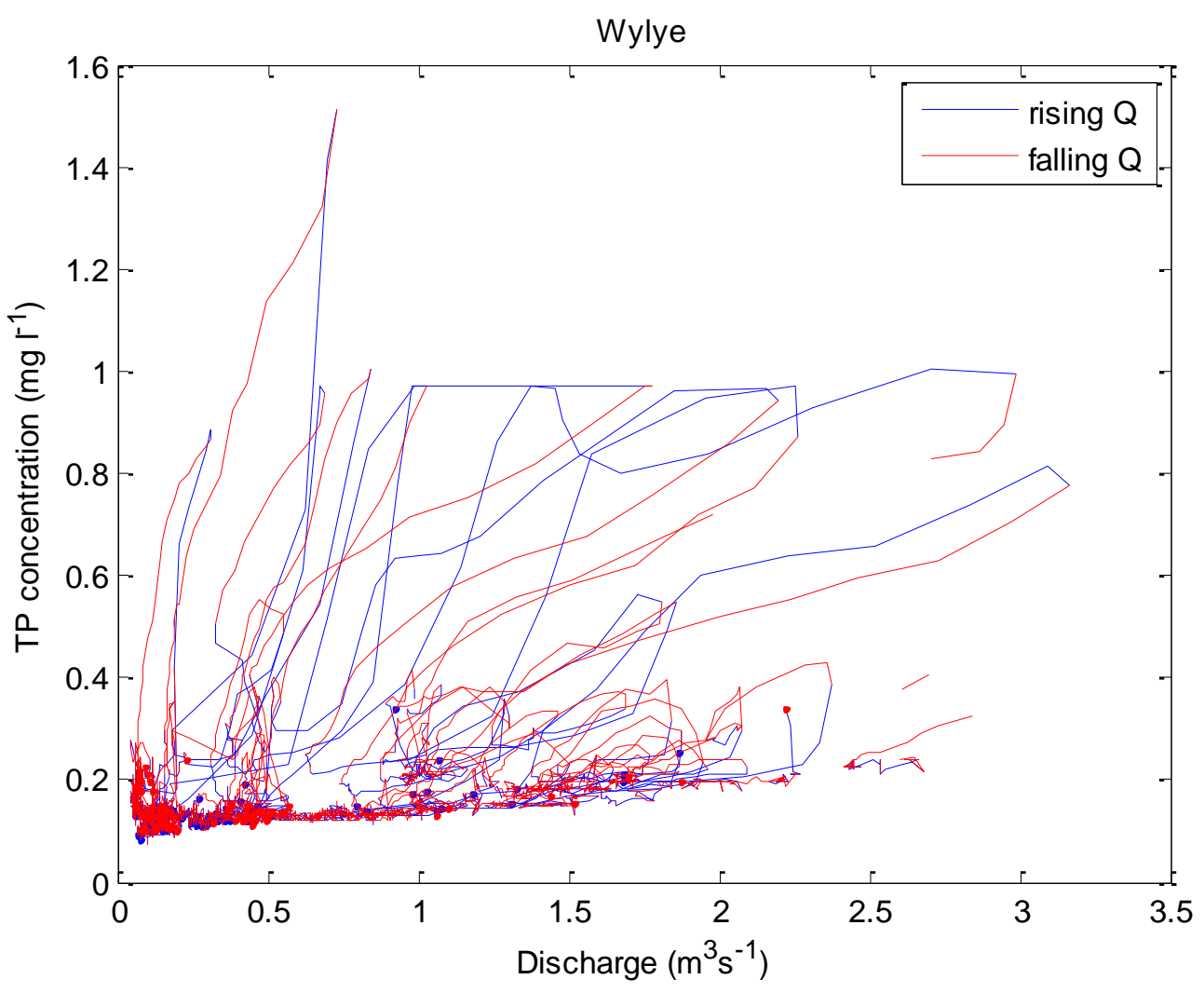


Figure S4

Hourly streamflow (Q) against total phosphorus (TP) load for the Newby Beck catchment, with the rising limb of storm hydrographs in blue and the falling limb of hydrographs in red.

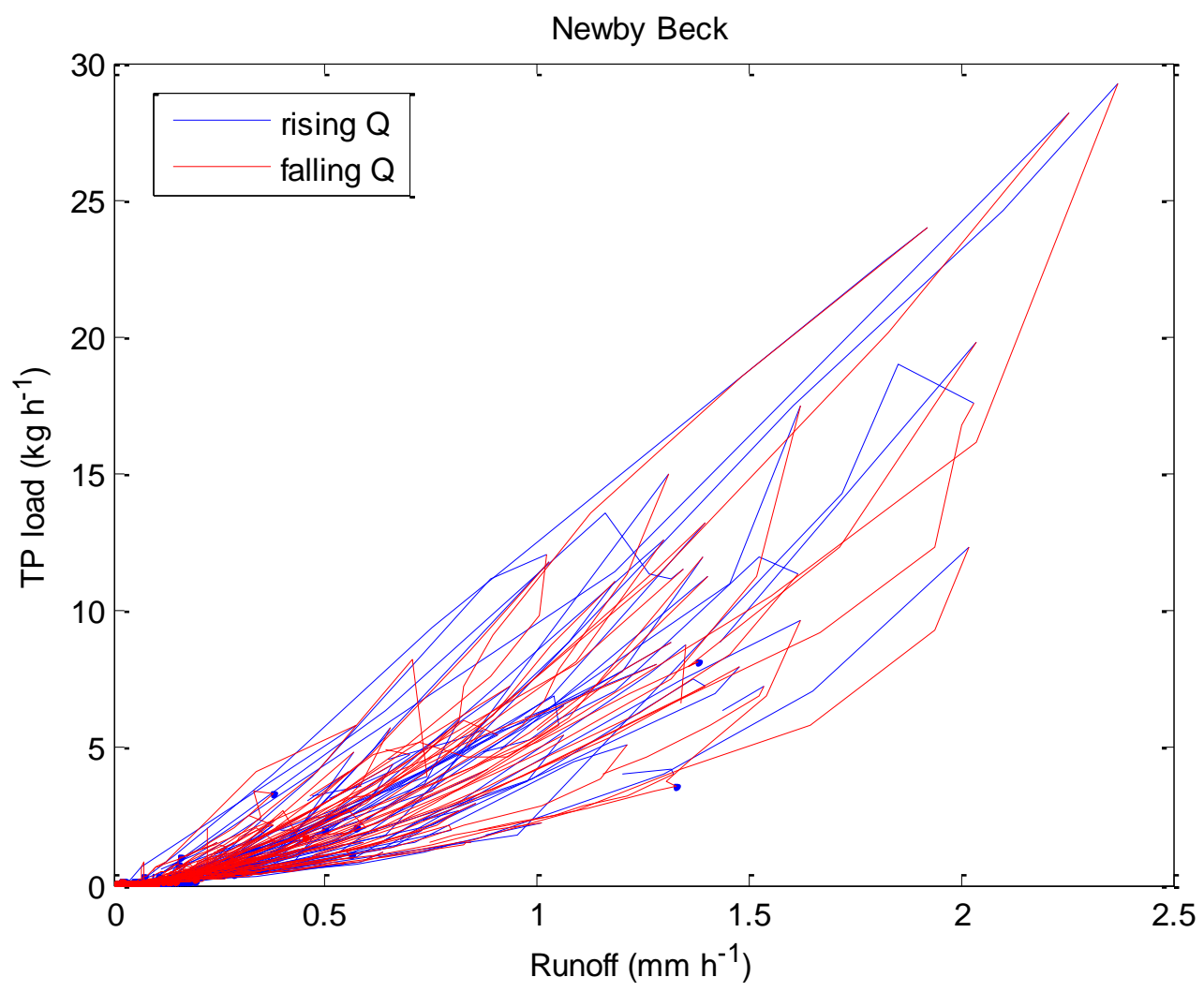


Figure S5

Hourly streamflow (Q) against total phosphorus (TP) load for the Blackwater catchment, with the rising limb of storm hydrographs in blue and the falling limb of hydrographs in red.

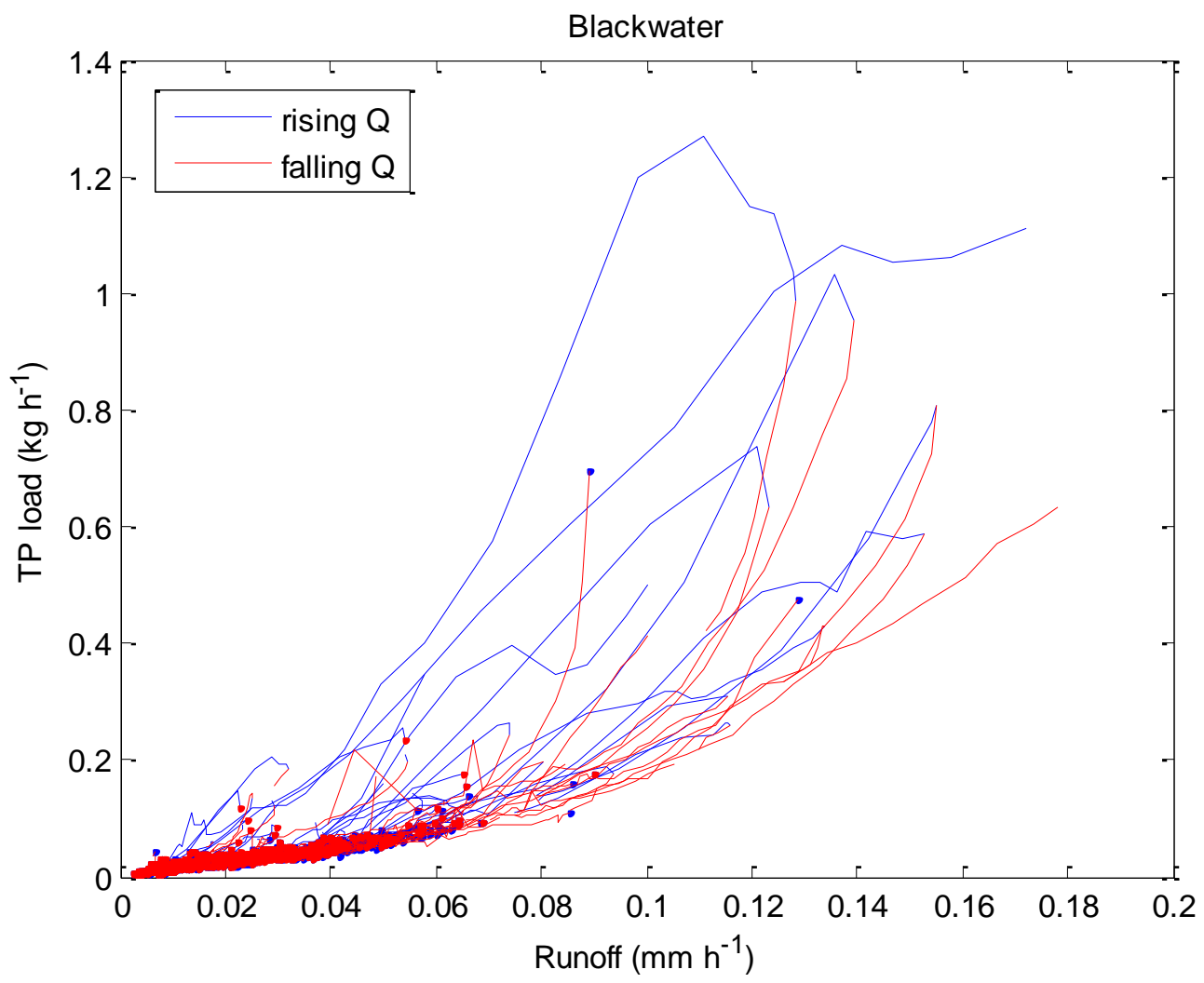


Figure S6

Hourly streamflow (Q) against total phosphorus (TP) load for the Wylye catchment, with the rising limb of storm hydrographs in blue and the falling limb of hydrographs in red.

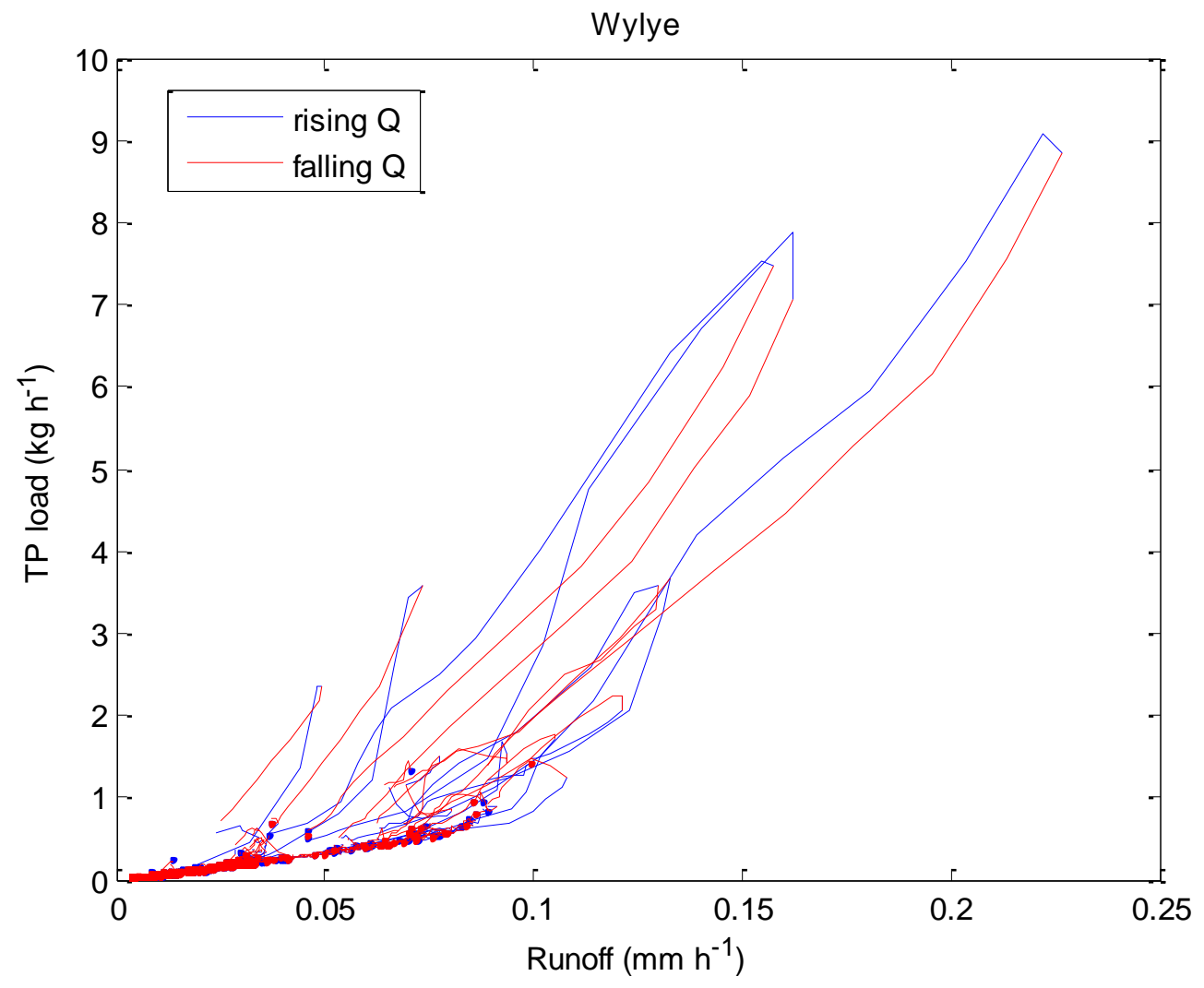


Figure S7

Time series of residuals and histogram of residuals for Figure 3
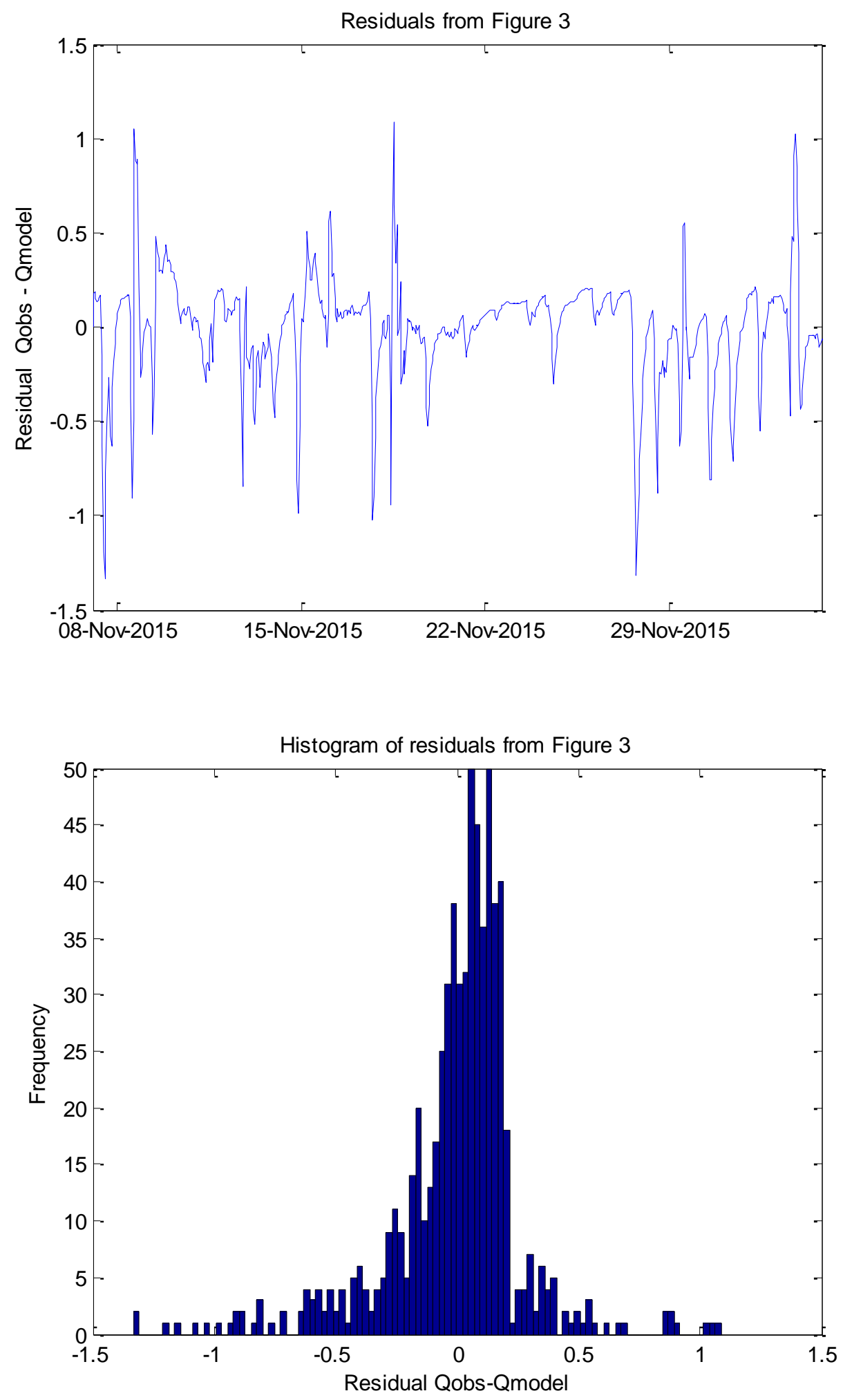
Figure S8

Time series of residuals and histogram of residuals for Figure 4
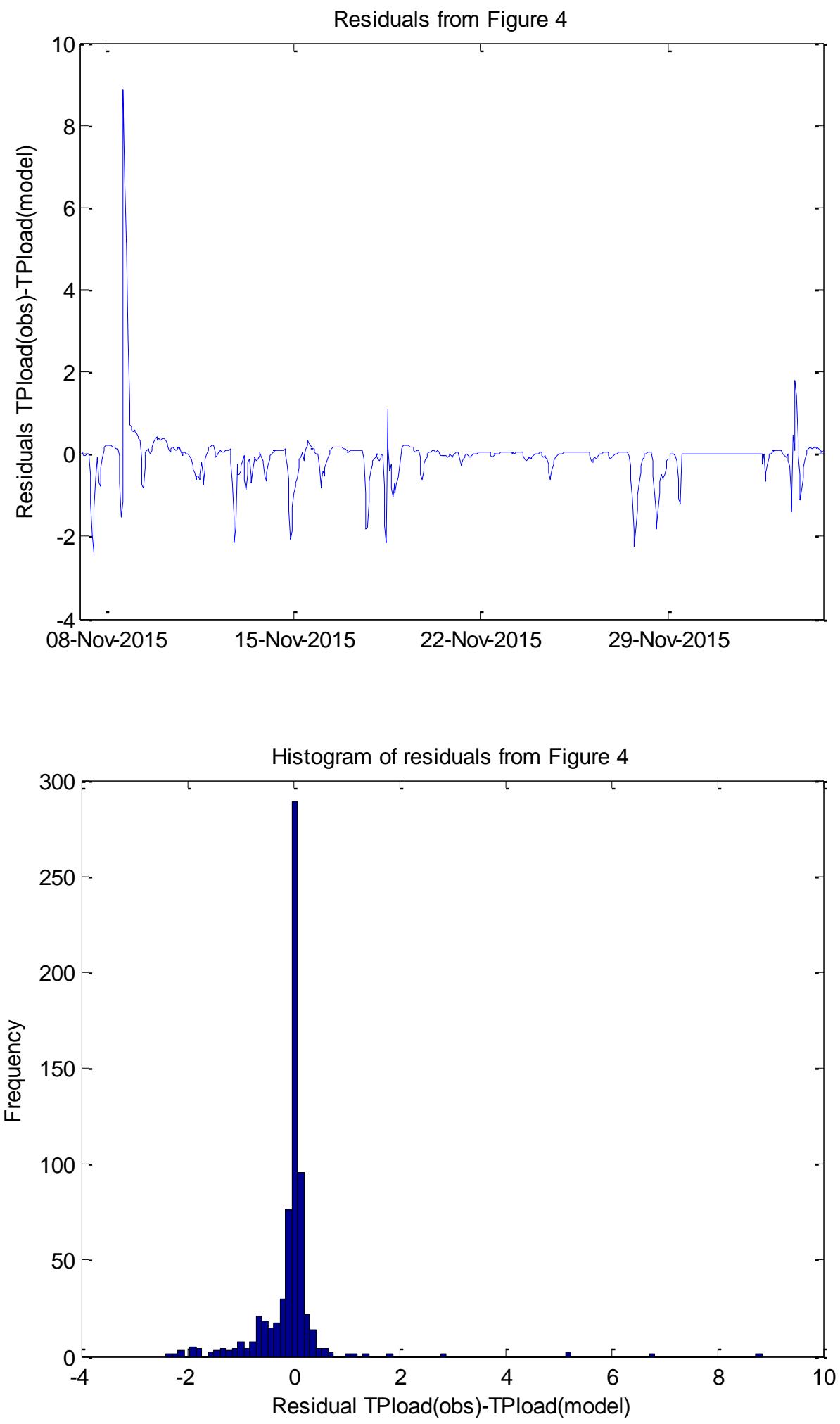
Figure S9

Discharge model, Newby Beck: Time series of residuals (top); residuals against discharge per unit area (bottom)
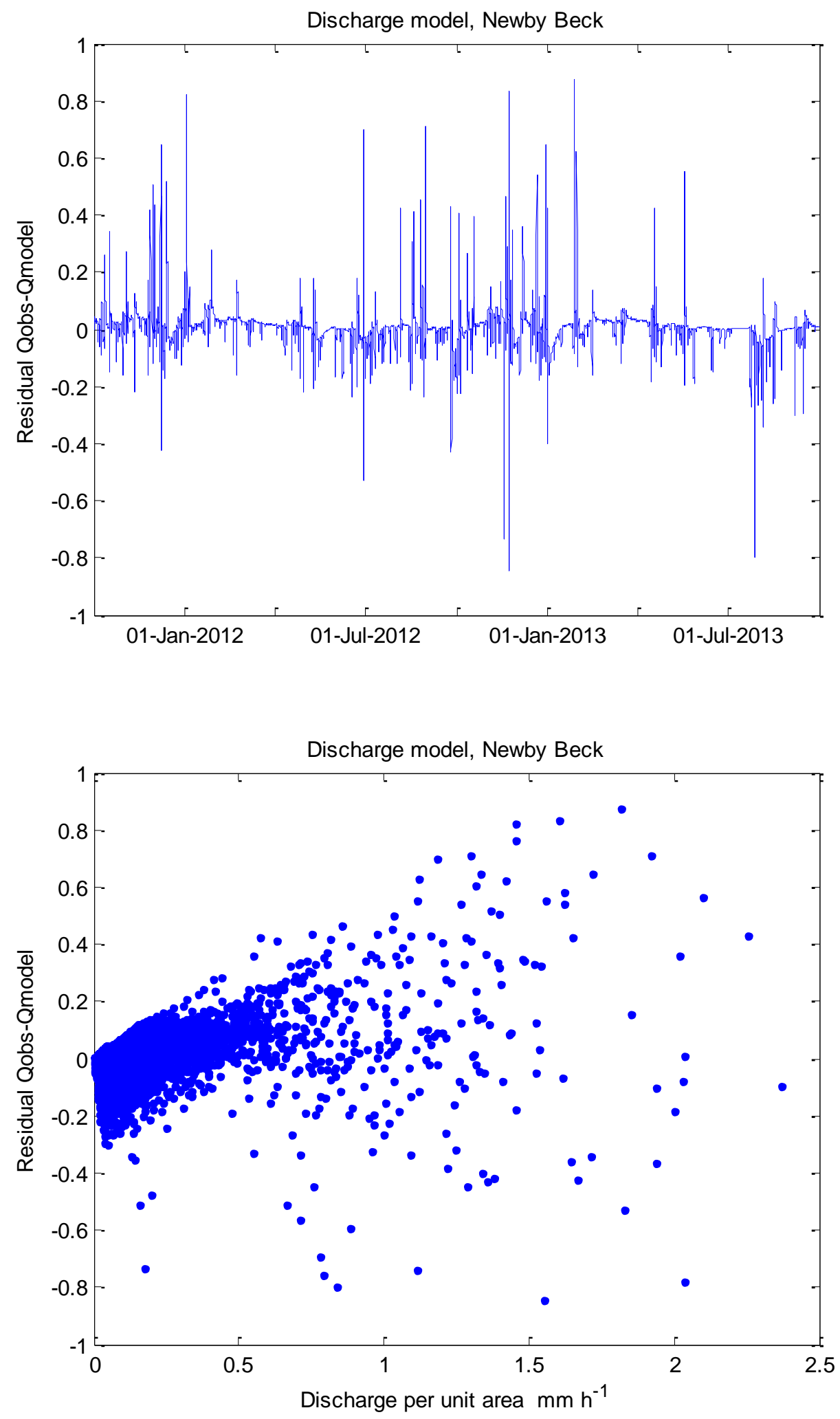
Figure S10

TP load model, Newby Beck: Time series of residuals (top); residuals against TP load (bottom)
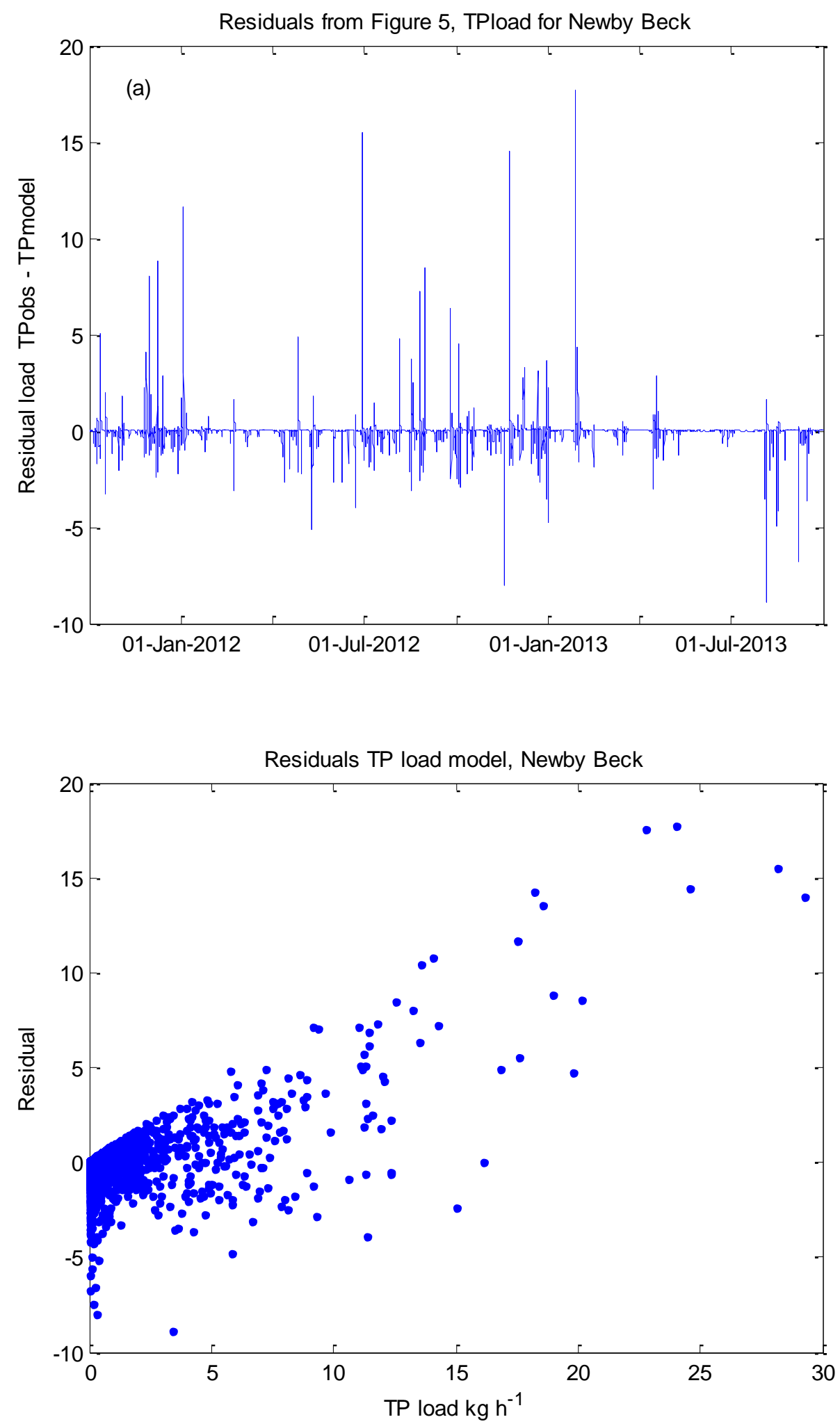
Figure S11

Discharge model, Wylye: Time series of residuals (top); residuals against discharge per unit area (bottom)
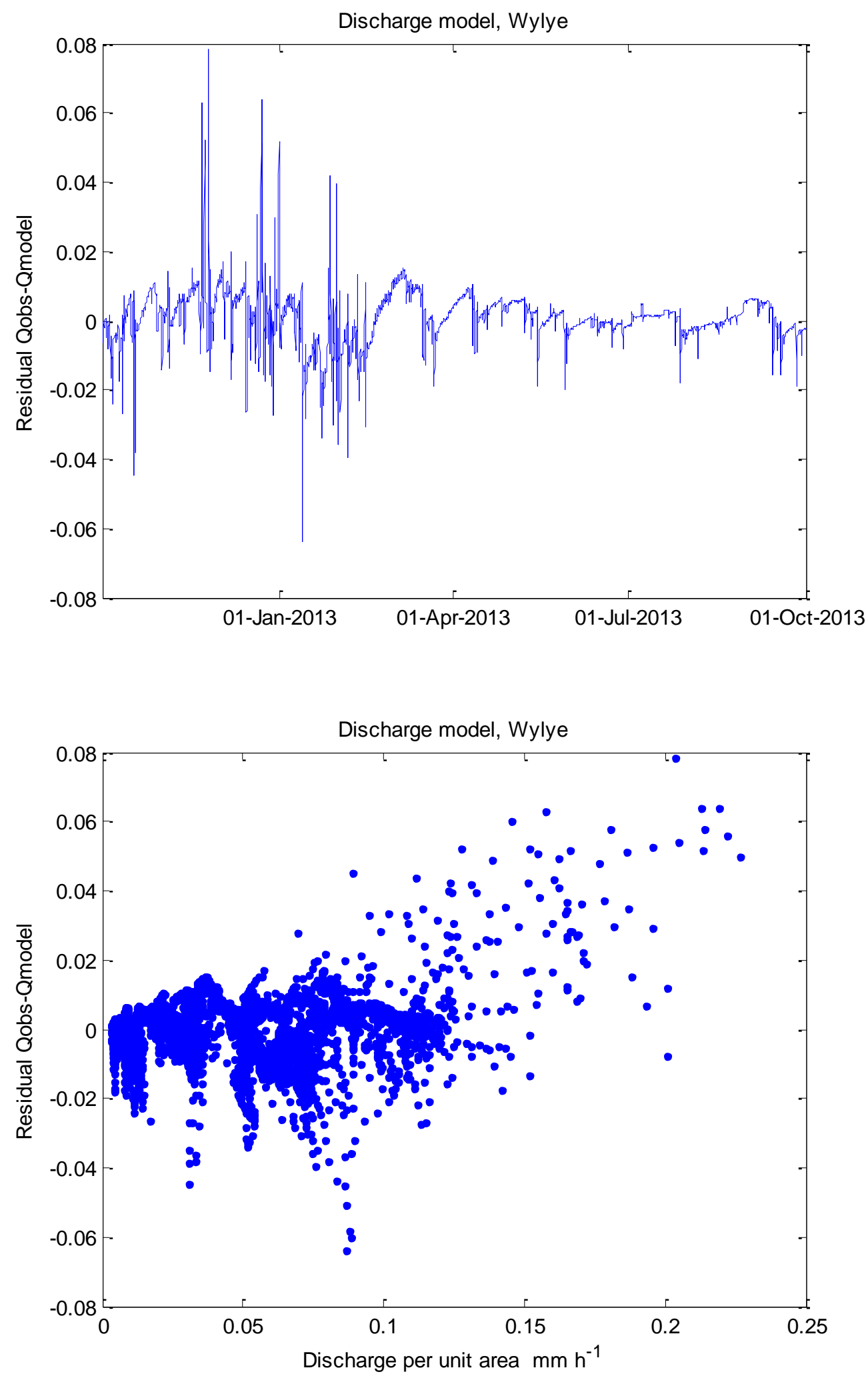
Figure S12

TP load model, Wylye: Time series of residuals (top) residuals against TP load (bottom)
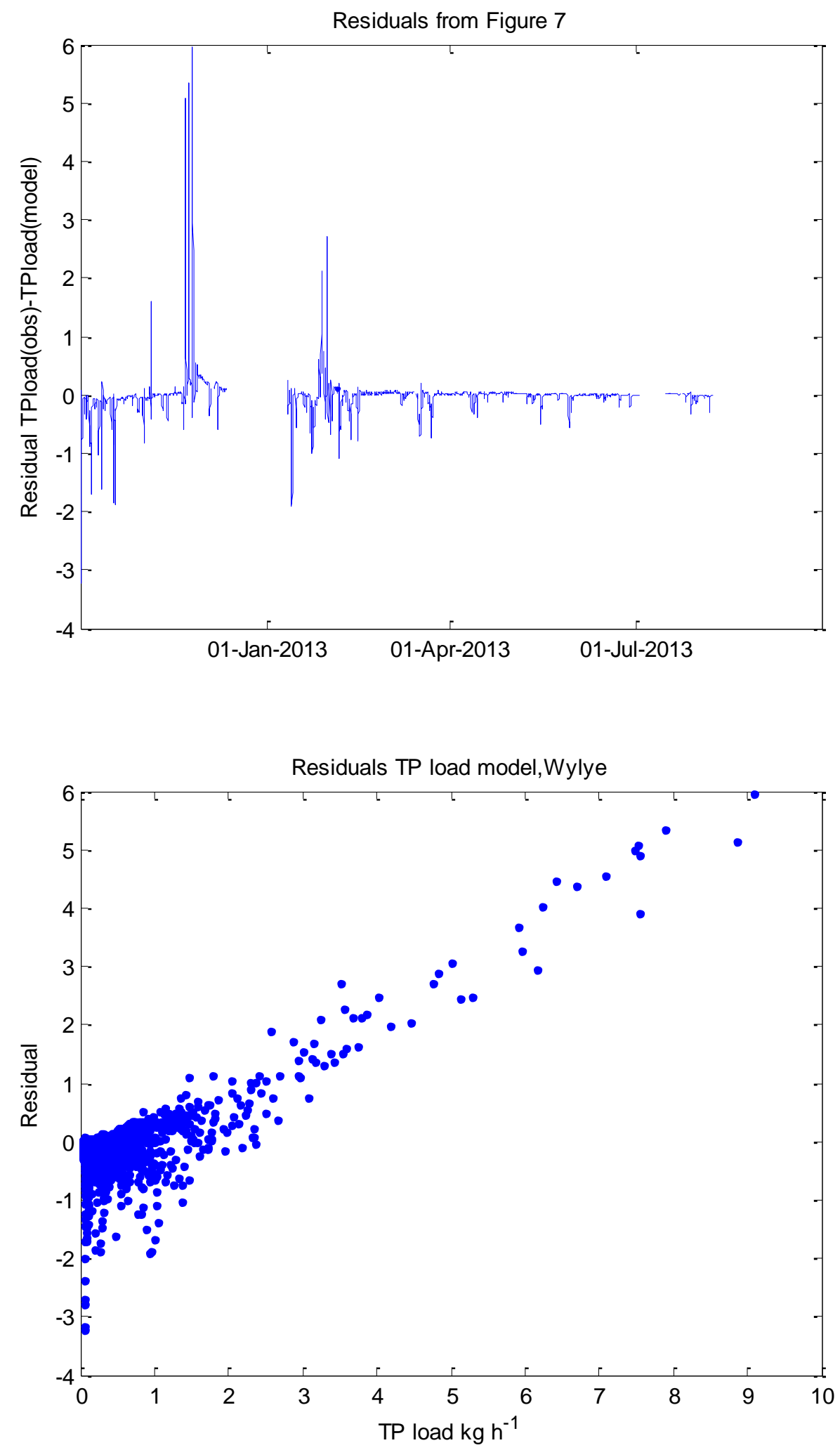
Figure S13

Discharge model, Blackwater: Time series of residuals (top); residuals against discharge per unit area (bottom)
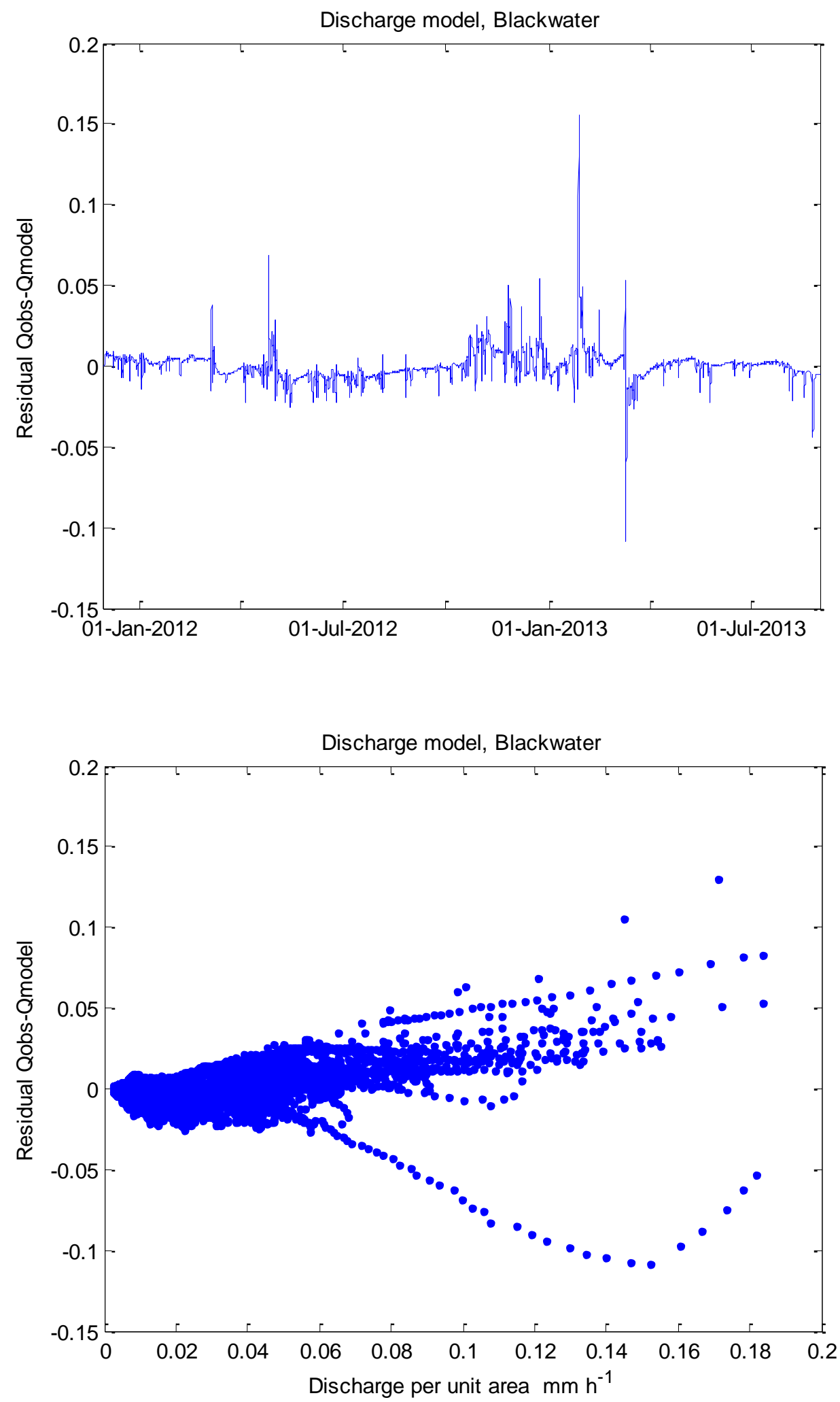
Figure S14

TP load model, Blackwater: Time series of residuals (top); residuals against TP load (bottom)
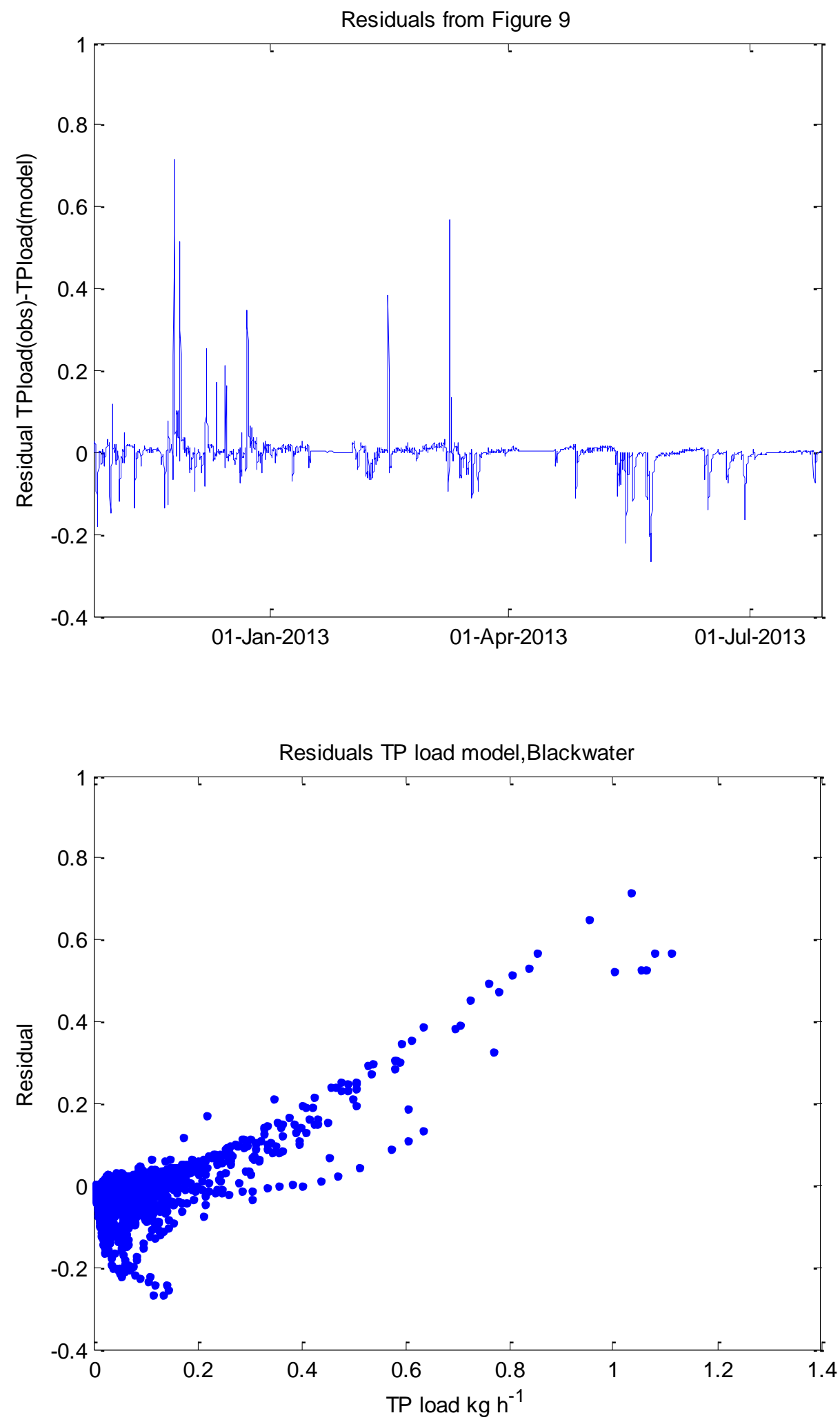
Figure S15

Discharge model (a) and TP load model (b) for validation period, Newby Beck
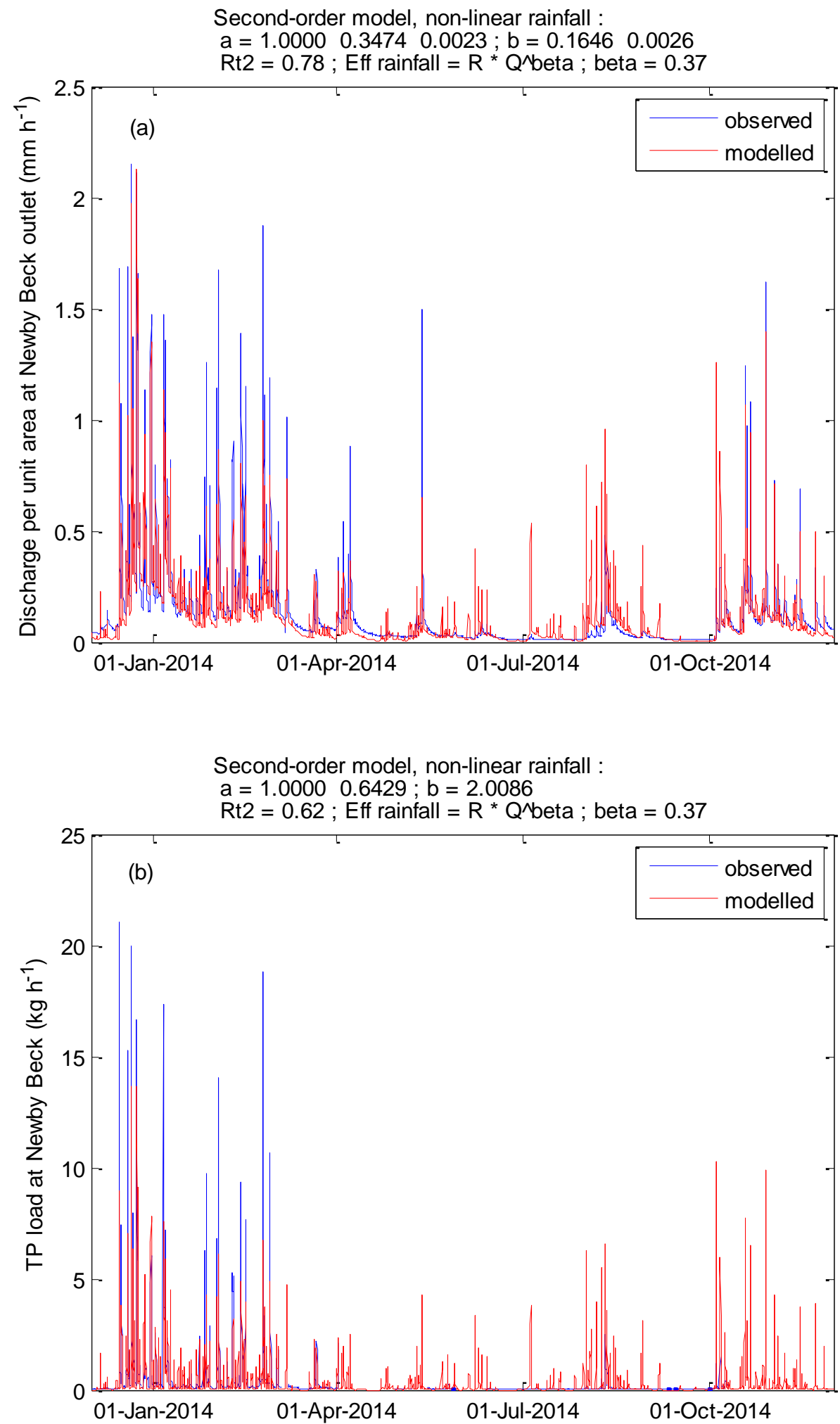
Figure S16

Discharge model (a) and TP load model (b) for validation period, Wylye

Second-order discrete-time model, non-linear rainfall :

$a=1.0000-1.7785 \quad 0.7791 ; b=0.0000 \quad 0.0000 \quad 0.0000 \quad 0.0000 \quad 0.0000 \quad 0.0000 \quad 0.0440-0.04 \varepsilon$ Rt2 $=0.79 ;$ Eff rainfall $=R^{*} Q^{\wedge}$ beta $;$ beta $=0.59$

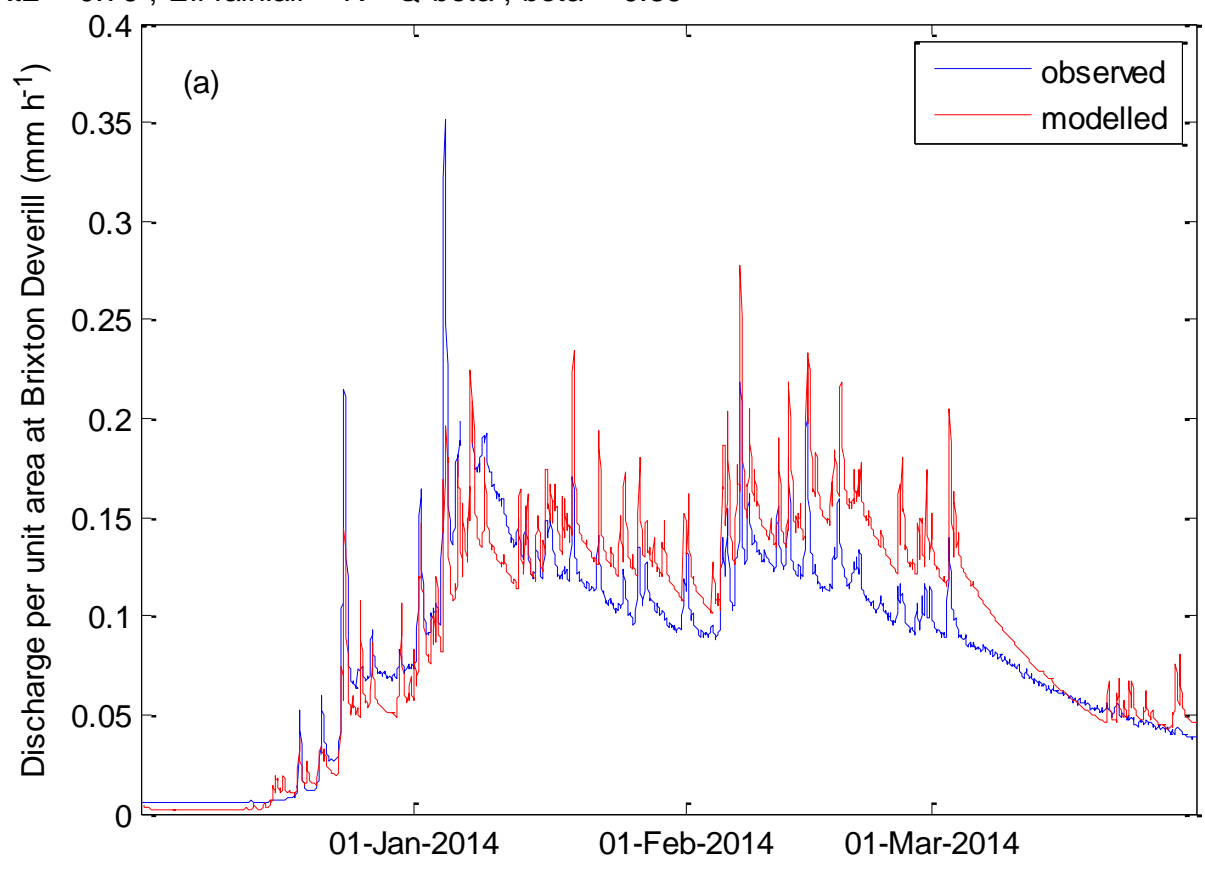

Second-order model, non-linear rainfall :

$a=1.0000 \quad 0.1660 \quad 0.0003 ; b=1.30160 .0054$

$\mathrm{Rt2}=0.50 ;$ Eff rainfall $=\mathrm{R}^{*} \mathrm{Q}^{\wedge}$ beta $;$ beta $=0.59$

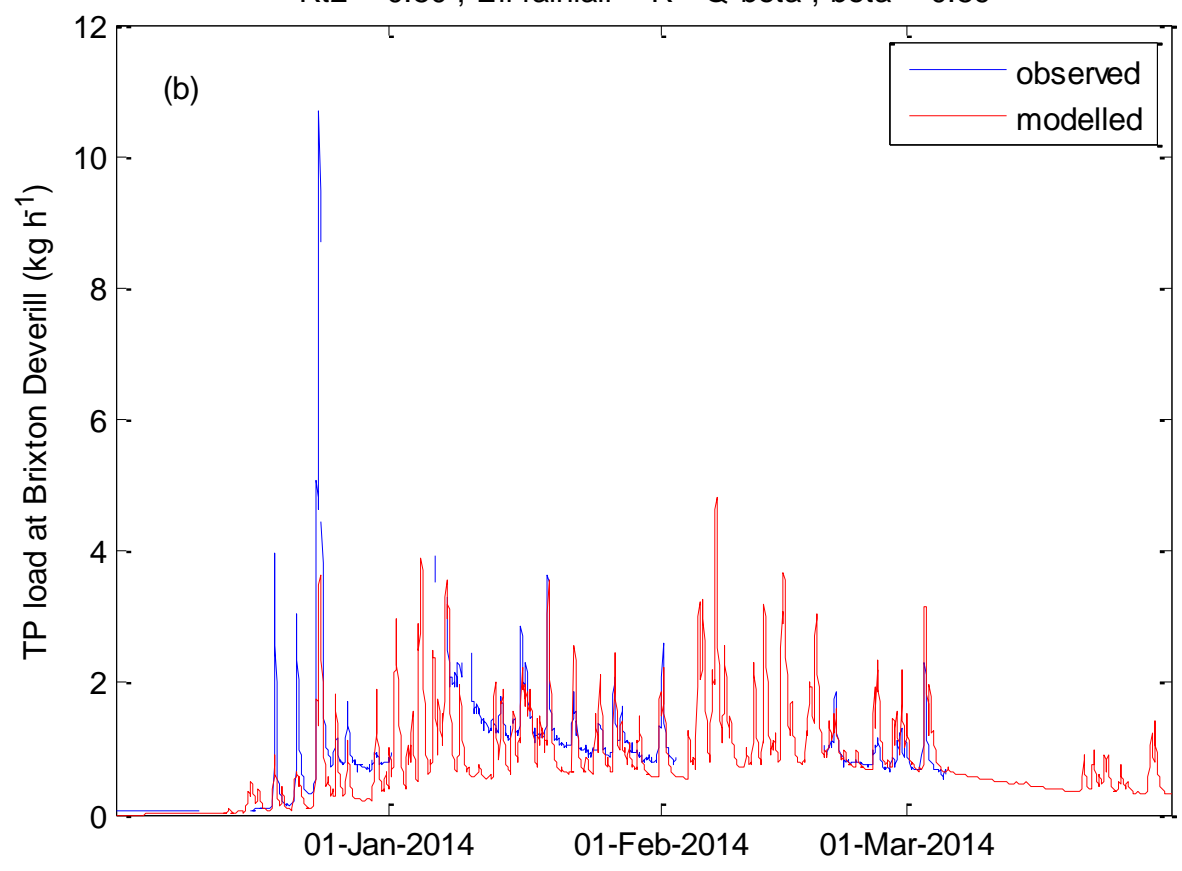


Figure S17

Discharge model for calibration period, Blackwater, where effective rainfall has been generated using Qobs (observations) (a) and using Qsim (simulation) (b), showing the poor fit which made Qsim unusable in the TPload model.

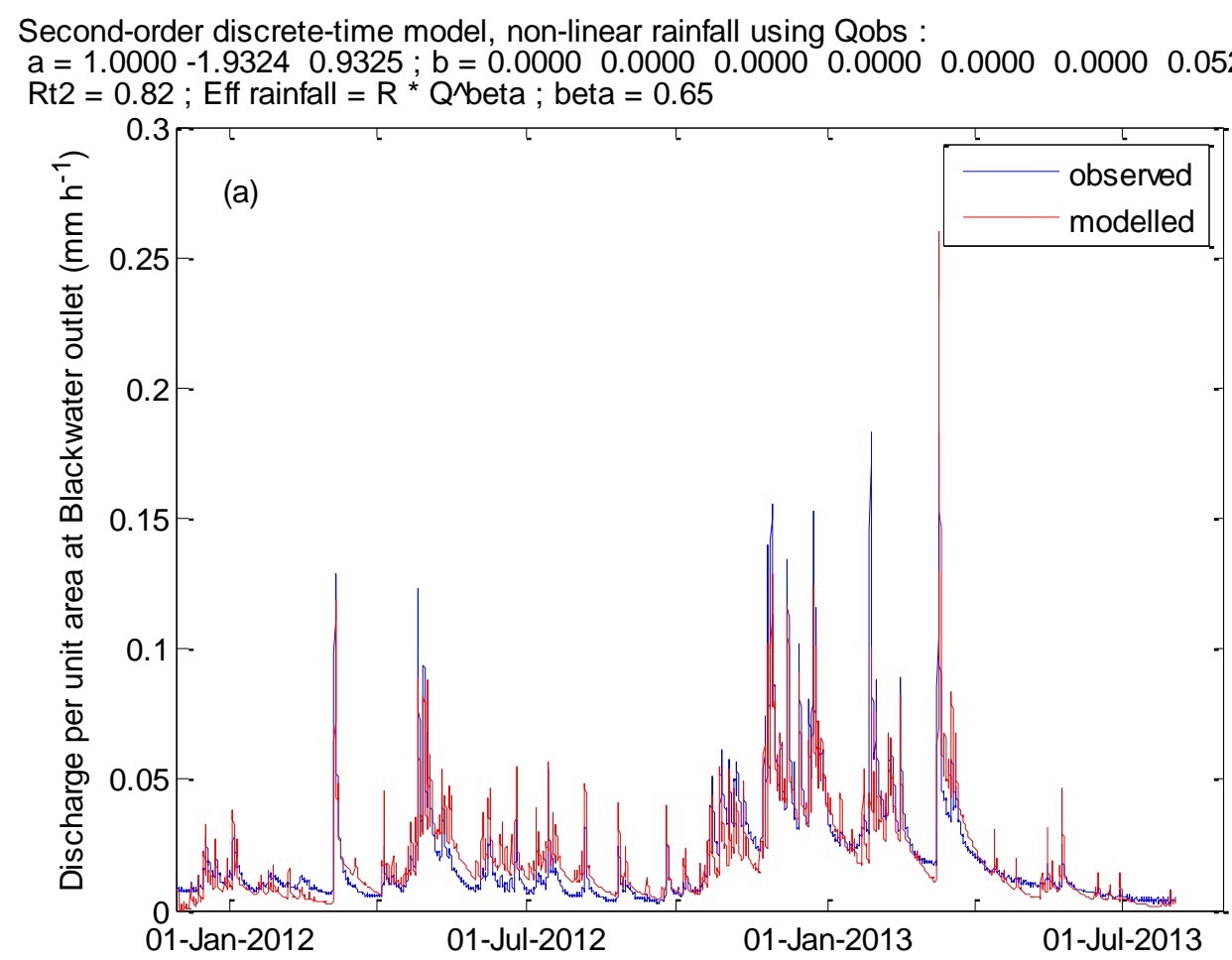

Second-order discrete-time model, non-linear rainfall using Qsim:

$a=1.0000-1.9324 \quad 0.9325 ; b=0.0000 \quad 0.0000 \quad 0.0000 \quad 0.0000 \quad 0.0000 \quad 0.0000 \quad 0.0526-0.052$ $\mathrm{Rt} 2=0.37 ;$ Eff rainfall $=\mathrm{R}^{*} \mathrm{Q}^{\wedge}$ beta $;$ beta $=0.65$

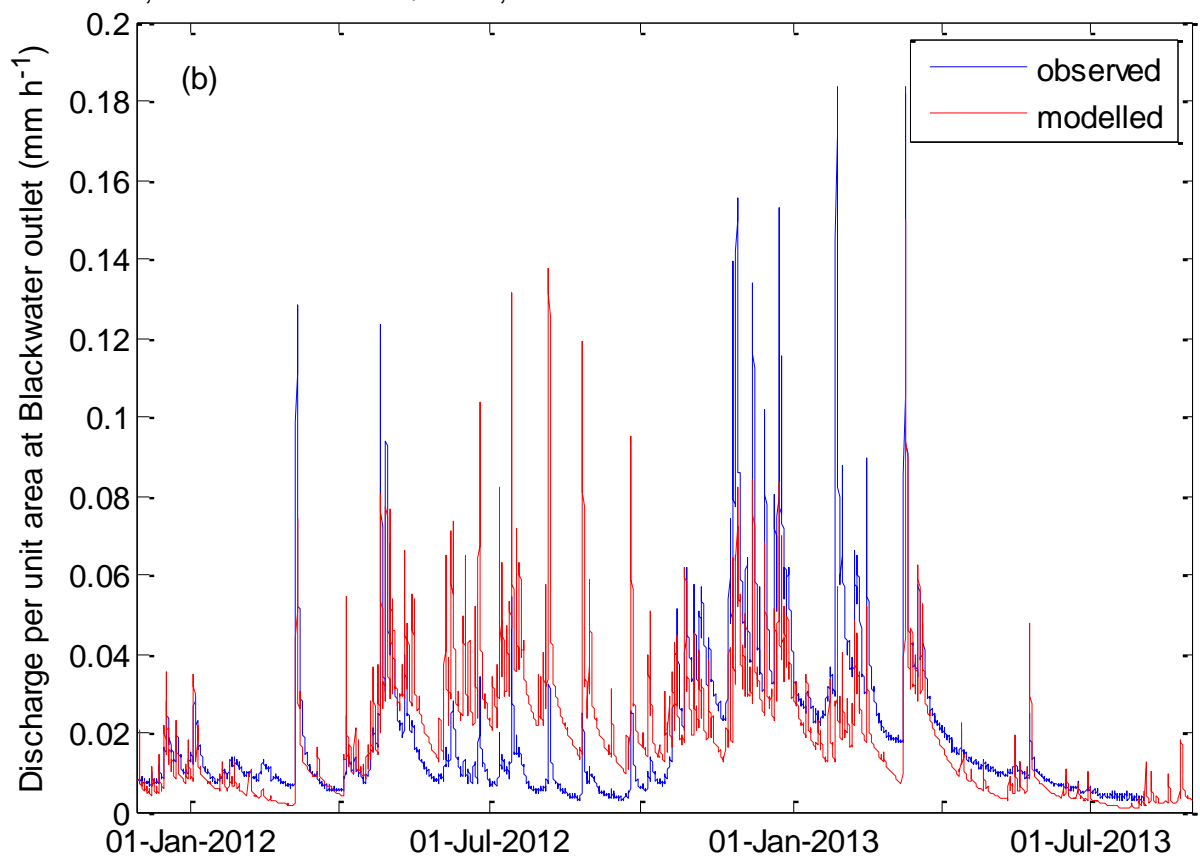


Figure S18

Discharge model (a) for validation period, Blackwater, showing poor fit which made effective rainfall unsuitable for use in the TP model; and TP model (b) for validation period using linear rainfall input
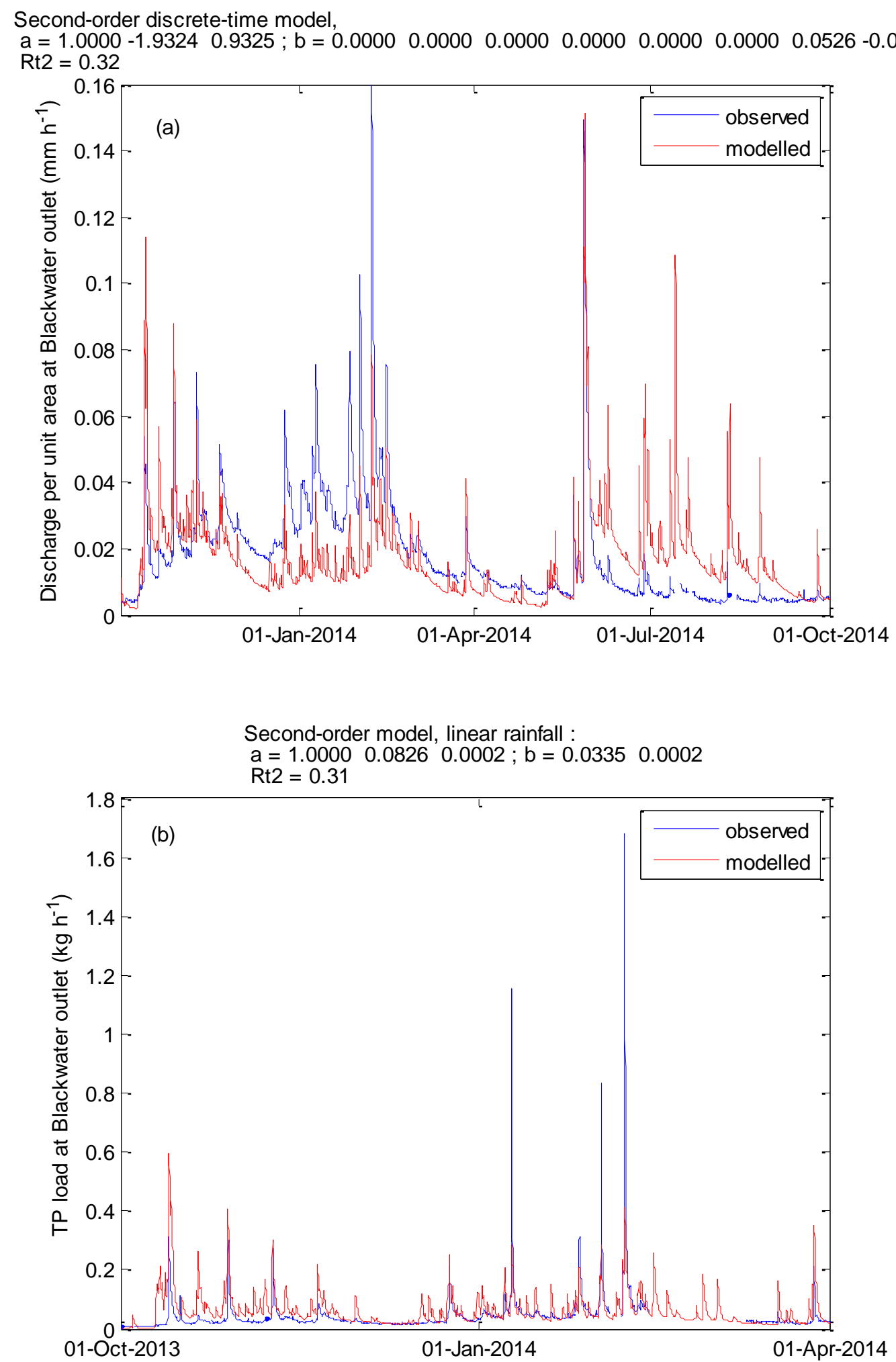
Supplementary references

Franklin, G. F., Powell, J. D., and Emami-Naeini, A.: Feedback Control of Dynamic Systems, 4th Edition, Prentice-Hall, 2002.

UKCP09: Gridded observation data sets:

http://www.metoffice.gov.uk/climatechange/science/monitoring/ukcp09/ access: 18 August 2015, 2009.

Ockenden, M. C., Hollaway, M. J., Beven, K., Collins, A. L., Evans, R., Falloon, P., Forber, K. J., Hiscock, K. M., Kahana, R., Macleod, C. J. A., Tych, W., Villamizar, M. L., Wearing, C., Withers, P. J. A., Zhou, J. G., Barker, P. A., Burke, S., Freer, J. E., Johnes, P., Snell, M. A., Surridge, B. W. J., and Haygarth, P. M.: Major agricultural changes required to mitigate phosphorus losses under climate change, Nat Commun, 10.1038/s41467-017-00232-0, 2017.

Robson, A., and Reed, D.: Flood Estimation Handbook - FEH CD-ROM 3, Institute of Hydrology, Wallingford, 1999.

Soil Survey of England and Wales: Legend for the 1:250,000 Soil Map of England and Wales, Soil Survey of England and Wales, Rothamsted Experimental Station, Harpenden, 1983.

Young, P. C.: Recursive Estimation and Time-Series Analysis, Springer-Verlag, Berlin, 1984. 